\title{
Le Pr Marc Lémann nous a quittés
}

\section{A. Senéjoux $\cdot$ et tout le comité de rédaction}

C Springer-Verlag France 2010

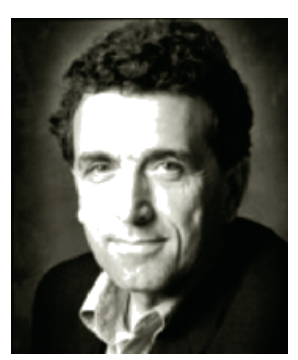

Très cher Marc,

Cette dernière lettre que je t'écris est certainement la plus difficile à bâtir, à façonner... L'émotion de l'annonce de ta disparition est bien trop vive pour que les mots s'imbriquent facilement les uns aux autres... Ton décès si brutal résonne si fort à mes oreilles. Comment croire que jamais plus tu ne seras là ? En cette fin d'été, certains ont dû penser à une mauvaise plaisanterie. Ironie du sort quand même, c'est presque toi qui nous l'as faite, cette blague, en partant pendant les vacances, toi qui préférais le labeur à l'oisiveté, allant même jusqu'à trouver que cette longue pause estivale c'était mortel... Et pourtant... Même si tu ne te lèveras plus dans un amphithéâtre de congrès pour poser la bonne question, tellement à l'aise avec ta vieille veste hors du temps et ton anglais inimitable; même si les malades pleureront ton oreille attentive et tes collègues ta disponibilité indéfectible, tu demeureras longtemps parmi nous. Tu disais, il me semble, que personne n'est irremplaçable... Il est bien difficile aujourd'hui de le penser... Mais ton souhait le plus cher était certainement que la vie continue... que chacun se mette à la tâche pour perpétuer ta mémoire à travers notre travail... Alors, nous continuerons, c'est promis... Tu nous as tant appris... Jamais avare de tes conseils... Je me souviens de ce vieil hôpital Saint-Lazare où je t'avais croisé, petite externe timide... de Saint-Louis, plus tard où interne j'ai eu tant de plaisir à pouvoir compter sur toi tant pour prendre en charge tous ces malades atteints de MICI que pour préparer mon mémoire de DES et ma thèse... Je me rappelle d'une escapade avec toi une nuit aux archives de Saint-Lazare, à la recherche de précieuses données au fin fond de gros dossiers... Et plus tard des réunions au GETAID, ce si bel exemple de collaboration multicentrique, cette force vive et productive que nous envient bien des spécialistes des MICI de l'autre côté de l'Atlantique... Qui aurait pu imaginer que le président de ce magnifique outil laisserait son fauteuil vacant... Tous tes collègues se souviendront de ton esprit si vif, si brillant, mais aussi de ta modestie, de ta capacité à ne pas te mettre en avant...

$\mathrm{Tu}$ laisses un immense vide Marc... Tu vas nous manquer, tu vas me manquer...

A. Senéjoux $(\bowtie)$

e-mail : agnes.senejoux@gmail.com 